\title{
Notes de lecture
}

\section{Rosemary Elizabeth Gall, People's Spaces and States Spaces. Land and Governance in Mozambique, 2003, Oxford, Lexington Books, 328 p., ISBN : 07-391-0632-5.}

Rosemary Galli nous plonge dans l'histoire sociale, économique et politique de quatre «petites » communautés rurales mozambicaines, des années 1930 à 2000 : les communautés de Kalanje dans le district de Sanga au nord du pays (province de Niassa), de Kanda au centre (district Gorongosa) et deux communautés Chaiva dans le district Mossurize, au sud du Mozambique. En effet, à partir des années 1990, l'auteure a accompagné neuf ans durant, au sein de l'Instituto nacional de desenvolvimento rural (INDER) financé par des bailleurs internationaux, un programme national de planification d'aide au retour à la terre des populations rurales réfugiées suite à la guerre civile.

C'est une véritable histoire analytique des rapports entre un gouvernement, à la logique centralisatrice, et sa population que Rosemary nous livre. Les communautés rurales ont traversé les conquêtes coloniales en s'y adaptant, tout en préservant leurs caractéristiques organisationnelles, culturelles et économiques. Leur intégrité et leur cohésion historiquement conservées fondent leur grande flexibilité face aux changements intervenus du fait de la guerre. En se basant sur la capacité d'adaptation de ces communautés, l'auteure et son équipe imaginent une nouvelle façon d'appréhender la planification des retours et incitent le gouvernement à passer d'une gestion technobureaucratique à une approche plus participative. Celle-ci consiste à demander aux gens comment les aider à planifier eux-mêmes leur territoire. L'ouvrage démontre ainsi de manière très éclairante, à quel point l'implication des populations locales est nécessaire à l'implantation des programmes nationaux: sans cette participation décisive, le programme, dans sa conception originelle, aurait conduit au simple gaspillage de millions de dollars.

\section{Mai 2005, Marion Gret}

\section{Global Witness, Les affaires sous la guerre: armes, pétrole et argent sale en Angola, Marseille, Agone, 2003, 230 p., ISBN : 2-910846-90-3 ("Les "dossiers noirs" d'Agir ici \& Survie ", 18).}

Roman policier ou livre d'histoire? On est un peu dans les deux ambiances en lisant ce rapport d'enquêtes, fruit des travaux de journalistes et de militants, regroupés par l'ONG Global Witness (témoin mondial), dans une traduction française qui s'ajoute à la collection des Dossiers noirs publiées à l'initiative des associations françaises Agir Ici et Survie. Le texte complet, ainsi que certains autres de la même veine, est accessible sur le site de Global Witness, <www.globalwitness.com>, en anglais, portugais et français. Les informations présentées dans ce rapport sont tirées d'articles de presse, tous donnés en références, ainsi que de données obtenues grâce à des investigations approfondies menées en 2000 et 2001. 